\title{
Methodology for the Analysis of Simulation-based Decision-making in the Manufacturing Area
}

\author{
Gert Zülch, Thilo Gamber and Patricia Stock \\ University of Karlsruhe, ifab-Institute of Human and Industrial \\ Engineering, Kaiserstrasse 12, D-76131 Karlsruhe, Germany \\ \{zuelch, gamber, stock\}@ifab.uni-karlsruhe.de, \\ WWW home page: http://www.ifab.uni-karlsruhe.de
}

\begin{abstract}
Growing market demands on enterprises and the resulting challenges for their organization have been discussed for many years now. The flexibility and mutability of an enterprise are thereby considered as a significant factor for success. As a reaction to this, many enterprises have realigned their enterprise along the value-added chain. The implementation of flat hierarchies and process-oriented work organization make up focus of current discussions about organizational structures in the manufacturing area. New departmental structures, however, often require that decisions are delegated to operative positions, thus increasing the decision-making and action leeway of the operative employees. However, there are currently no methods capable of prospectively examining the suitability of such decentralized decision-making systems. In this context, this paper presents a method with which the suitability of decision-making systems can be examined in a prospective and quantitative manner. In order to attain this goal, the simulation procedure OSim-Ent developed at the ifab-Institute of Human and Industrial Engineering of the University of Karlsruhe (Germany), was expanded through generic elements, with which relevant decision-making system elements can be modeled and examined through simulation.
\end{abstract}

Keywords

production planning and control, decision-making system, personnel-oriented simulation

Please use the following format when citing this chapter:

Zülch, G., Gamber, T., Stock, P., 2007, in IFIP International Federation for Information Processing, Volume 246, Advances in Production Management Systems, eds. Olhager, J., Persson, F., (Boston: Springer), pp. 337-344. 


\section{New Demands on Manufacturing Systems}

Enterprises in the manufacturing area normally pursue various, partially conflicting goals. One can distinguish between customer-related goals, such as the demand for short delivery times and a high degree of due date adherence, and enterprise-related goals, such as the endeavour to attain a high and even resource utilisation as well as a low capital tied-up, which should be realised to the best degree possible with the help of a suitable manufacturing control (e.g. see [1, p. 19 ff.]). However, in the past few years the enterprises' situation has been aggravated by changes of the market as well as by a rapid progress in technology. Beside cost and quality, time has taken on an increasingly important role, forcing enterprises to become ever more dynamic and versatile [2, pp. 155]. Conventional organisational structures have often an issue with the handling of such an agile environment [2, p. 156]. In current discussions about organizational configuration approaches in the manufacturing area, one can notice two trends of decentralization:

- New approaches for the organization of manufacturing systems have achieved growing attention since the beginning of the eighties from research and industry. The trend is moving to self-organising concepts, often referred to as Intelligent Manufacturing Systems (IMS). The core of self-organization is that a system achieves a stable state without interference from outside and especially without a central control [3]. For example, the concepts of Holonic Manufacturing System, the Fractal Factory or the Bionic Manufacturing work out this paradigm for the context of production management [2, p. 158; 4, pp. 13].

- The introduction of flat hierarchies into operations organization is seen as a fundamental factor for success (cf. e.g. [5, p. 71; 6, pp. 12]). Flat hierarchies, however, require a decentralized decision-making system, i.e. the required decisions have to be delegated to operative positions thus significantly increasing the decision-making and action leeway of the employees.

Currently, there is no method allowing for a prospective examination of the suitability of such decentralized decision-making systems (cf. [7, pp. 44]), in particular while considering the interdependency of operative decisions and efficient manufacturing operations. The question, as to whether the delegation of operative decisions to employees in the lower levels of the hierarchy is actually advantageous in a certain manufacturing system and dependent upon the given order program, has, therefore, yet to be answered. The quality of the decision-making system (in terms of the decision-making processes and decision makers' abilities) is thus dependent upon the knowledge and experience of the organizer.

In this context, this paper presents a methodology for the examination of the suitability of decision-making systems in a prospective and quantitative manner. In order to attain this goal, the simulation procedure OSim-Ent (German acronym for Object Simulator for Operative Decisions; see for OSim e.g. [8, 9]; for OSim-Ent [7]) developed at the ifab-Institute of Human and Industrial Engineering of the University of Karlsruhe, was expanded through generic elements, with which relevant decisionmaking system elements in manufacturing systems can be represented and examined through simulation. Thereby, the paper focuses on personel-centred decision-making systems. Nevertheless, the generic architecture of OSim would also allow for the 
implementation of algorithmic and self-organizing decision-making systems (e.g. see [10]).

\section{Decisions and Decision-making Systems in Manufacturing}

In order to make decisions, goals must first be defined. One can thereby differentiate between strategic and operative goals. In the following, merely operative decisions in the manufacturing area are taken into consideration (for these kinds of decision $\mathrm{cf}$. e.g. [11, p. 68]). Furthermore, one can differentiate between global and local decisions (cf. [12]). A distinction between internal (e.g. "short lead times") and external goals (e.g. "high delivery reliability") can also be made [1, p. 20]. Finally, it cannot be assumed that decisions of the operative personnel will harmonize with the goals of the entire system (differentiation between personal and organizational goals $[13$, p. 24]).

The result of a decision is highly dependent upon the quality of the information, meaning its availability, its timeliness and its genuineness: The better the information, the better the foundation for an efficient decision. Operative decisions, in particular decisions made by manufacturing employees, are influenced by both shortterm, invariant information as well as by the dynamic manufacturing situations. In the face of these system dynamics, it seems promising to analyze decision-making systems prospectively through simulation in order to help create suitable configuration solutions.

Finally, the decision-making strategy must also be specified, which the decisionmaker applies in order to select the best action alternative regarding the relevant goal system. The decision-making strategy joins components of the decision-making process to build up the decision.

Each decision is thus characterized by four elements: goal system, information system, decision-making strategy and decision maker, referred to in the following by the composite term decision field [7, pp. 82]. The entirety of the decision-making tasks and their respective decision fields makes up the decision-making system for the manufacturing system.

\section{Concept for Modeling Decision-making Systems}

Commercial simulation procedures possess only a limited ability to represent human decision-making, and in particular to vary the entire decision-making system. In order to make up for this deficit and to provide a simulation-based methodology for the planning of decision-making systems, the feasible decisions and decision-making strategies occurring in the manufacturing area, as well as the underlying goals and information, were first classified. A generic concept allowing decisions and decisionmaking systems to be modeled and then be evaluated with respect to their productions logistical and monetary goal criteria was subsequently derived.

The activities in the manufacturing system are modeled by so-called activity networks which are directed graphs with a logical sequence of activities for the 
winding-up of orders [9, p. 373]. A modeled manufacturing order program can thus be seen as a collection of activity networks. Activity networks can be released by external or internal events such as customer orders or internal requirement orders. In this way, it is also possible to model indirect activities [8, p. 373].

The spectrum of decisions arising in the manufacturing area is very broad. One can thereby differentiate between two types of decisions, which can be illustrated through varying representations of the decision nodes (cf. Fig.1):

- First, there are decisions which occur during the processing of an order (decision type a in Fig. 1), e.g. decisions about alternative work sequences, the order sequence or order lot sizes. In such decision-making tasks the various action alternatives are in competition with one another. Action alternatives can be illustrated by modeling the decision-making task as a decision node with alternative paths.

- Conversely, there are also decisions in a manufacturing system, which are independent upon a certain order (decision type b in Fig. 1), e.g. decisions about a short-term capacity increase through extended personnel working times. This type of decision cannot be modeled using activity nodes for alternative work sequences. Therefore, these decisions are modeled as decision nodes within a separate activity network, which arises either according to a fixed schedule or cyclically.

The decision nodes are assigned to one or more decision-making fields whose elements are specified as follows (cf. Fig. 1):

- The goal system presents assignment of relevant objectives from a catalogue of goals to the decision-making task. Employees from operative execution levels often act more in line with local goals that do management employees, who are primarily oriented towards global organizational goals ([14]; cf. also [13]).

- In addition to the differing goal systems of the various hierarchical levels, one must also assume a varying supply of information to the employees. Employees in the manufacturing system may also possess varying degrees of information [15], which may be dependent upon e.g. their functions or qualifications. Moreover, it can generally be assumed that the decision-maker does not have complete information. However, in the first step of the model creation, the last assumption was ignored and it was assumed that decisions are made based on complete information.

- In addition to the goals and the information available regarding the state of the manufacturing system, multi-criterion assessments are necessary in order to aggregate various goals e.g. through the application of additive or lexicographical preference functions.

- The decision-maker is either a foreman or an operative employee of the manufacturing system or a member of the centralized work planning department.

If a decision-making task is initiated during the simulation run, an assigned decision-making field is called upon. The decision-maker then makes a decision based on his decision-making strategy, which falls back on the goal system and the information available for the decision-maker (cf. [12]). In the simplest case, this can be carried out based on a multi-criterion assessment of the action alternatives. This means that the decision-maker evaluates the information about each action alternative with 
respect to his own goal system (e.g. using a lexicographic preference function) and then chooses the alternative promising the most benefit according to his goal system.

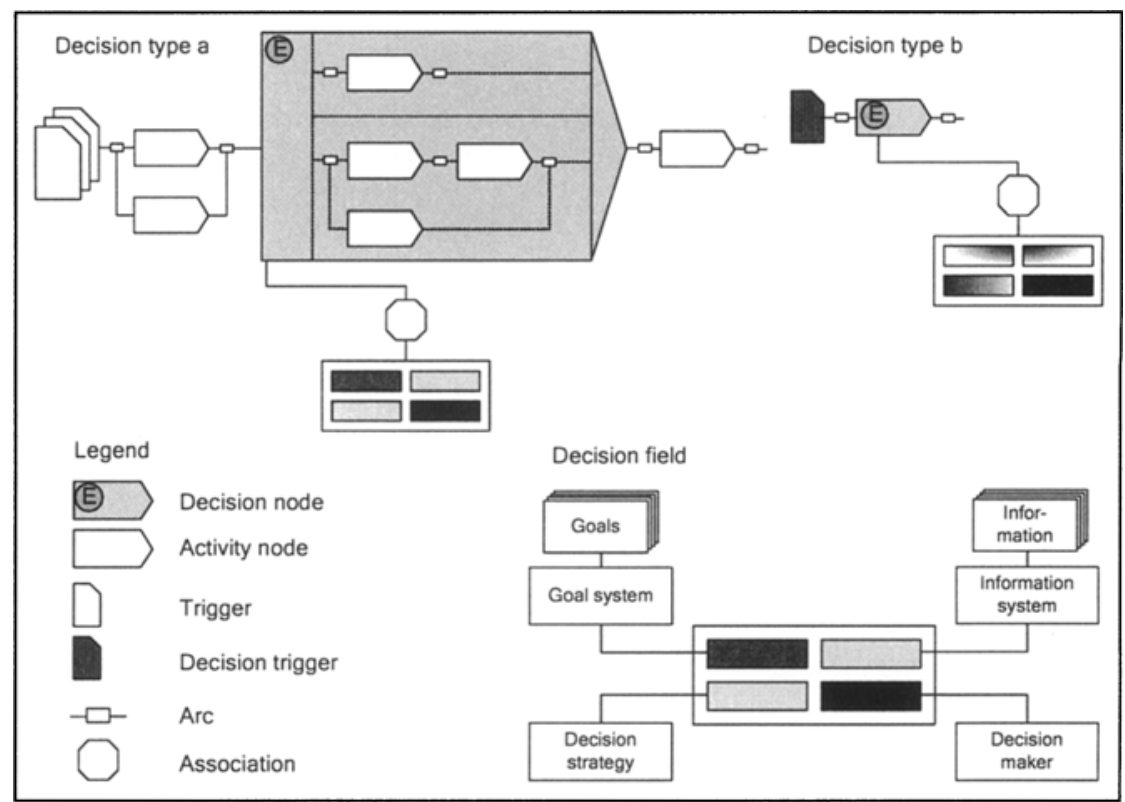

Fig. 1. Modeling decisions within the activity network (cf. [16, p. 102])

\section{The Simulation Procedure OSim-Ent}

The transfer of the modeling and assessment concept into the simulation procedure OSim-Ent (see Fig. 2) allows for a prospective and quantitative assessment of various decision-making systems. This enables the delegation of decisions to be planned more efficiently. Through simulation it is possible to assess decision-making systems and organizational structures (departmental and process organization) with respect to their efficiency and to derive configuration recommendations therefrom.

The modified simulation procedure OSim-Ent has been verified in test examinations. For this, several decision-making systems were modeled based on real manufacturing systems and then assessed:

- An ongoing simulation study investigates the manufacturing system of a mechanical parts manufacturer. In this parts manufacturing system, the modeled decisions concern the processing of jobs through a sequence of several single machines or a machining centre (i.e. decision type a; cf. Fig. 1). In the initial situation, the decision is made by chance whereas the probability of choice of each alternative is equal to $50 \%$. The performance of the manufacturing system and especially the lead time of the orders are poor. Therefore, several alternative 
decision-making systems are proposed and evaluated. The decision-making systems vary in the goal systems of the decision makers (e.g. different weighting factor for manufacturing costs and lead time) as well as in the decision-making strategy (e.g. additive or lexicographical preference function, maximin criterion). The first results are very promising. E.g. one decision-making system, which uses a lexicographical preference function, increased the goal achievement degree of the lead time by $4 \%$ and the goal achievement degree of the manufacturing costs by $11 \%$.

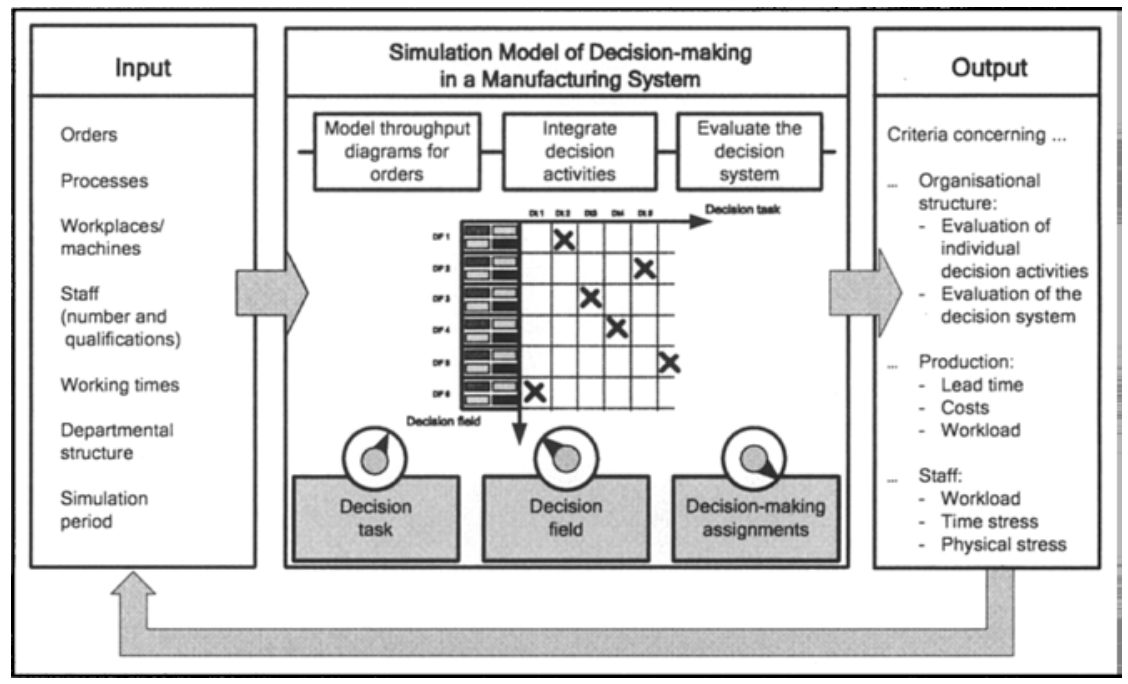

Fig. 2. The simulation procedure OSim-Ent (cf. [16, p. 105])

- Another project encompassed the improvement of disassembly and re-assembly processes for of electric devices. Therefore, a repair line, in which hammer drills in various weight classes are repaired, was chosen as the main object of investigation. The core problem was the broad variability of the temporal load to the system due to the heavy fluctuations in and the low predictability of the incoming orders. This had, on the one hand, a negative effect upon the service rate, while simultaneously creating disproportionately high idle-times. Therefore, the most important goal was to attain high service ability. In order to attain this goal, several strategies for the short-term employment of the staff were developed, e.g. "go home" or "help another employee". The foreman decided about the application of the strategies day-to-day, based upon information about the order waiting queues and the prognosis of the capacity requirements. In order to evaluate the strategies as well as the decision-making system, a simulation examination with OSim-Ent was conducted, using the decision type b for modeling (see Fig. 1). By this, very positive results could be attained, increasing the service degree by about $20-25 \%$ and reducing the idle times by $44 \%$ (please refer to $[7,12,17]$ for details of this project). 


\section{Further Research Needs}

The modeling and simulation of decision-making systems reveals as a great support for planners in the design of various decision-making systems. These can be assessed prospectively using the simulation procedure in order to identify improvement potentialities, and thus improve the organizational structure. The future aim is to build upon the insights gained in order to evaluate decisions made using elements of risk and uncertainty into the models.

The existing insights into the representation of human decision-making in manufacturing systems require further investigations. On the one hand, the quality of decision processes, with respect to their later effects, should be taken into account when modeling. Especially the efficiency of decision processes, i.e. their costs and duration, should be included into the decision process. On the other hand, the possibilities for creating an interface to algorithms and methods of artificial intelligence or for integrating learning decision-makers are also conceivable in order to improve the decision-making strategy, i.e. effectiveness of a decision.

\section{Acknowledgments}

The authors would like to thank the German Research Association (Deutsche Forschungsgemeinschaft - DFG) for its support in the research work referred to in this paper. These endeavours are currently supported within a project dealing with the development of a simulation-based method for the analysis of decision-making systems in the production area ("Entwicklung einer simulationsbasierten Methode zur Analyse von Entscheidungssystemen im Produktionsbereich").

\section{References}

\section{H. Lödding, Verfahren der Fertigungssteuerung (Springer, Berlin et al., 2005).}

2. J. Käschel and T. Teich, Produktionswirtschaft. Band 1: Grundlagen, Produktionsplanung und-steuerung (guc Verlag der Gesellschaft für Unternehmensrechnung und Controlling, Chemnitz, 2004).

\section{H. Haken, Synergetics (Springer, Berlin et al., 1983).}

4. A. Tharumarajah, From Fractals and Bionics to Holonics, in: Agent-based manufacturing: advances in the holonic approach, edited by S. M. Deen (Springer, Berlin et al., 2003), pp. 11-30.

5. S. Hauss and J. Brucke, Wettbewerbsfähig durch optimierte Organisationsstrukturen, VDI-Zeitschrift, 142(7/8), 71-73 (2000). 
6. E. Frese and A. v. Werder, Organisation als strategischer Wettbewerbsfaktor, in: Organisationsstrategien zur Sicherung der Wettbewerbsfähigkeit, edited by E. Frese and W. Maly (Verlagsgruppe Handelsblatt, Düsseldorf, 1994), pp. 1-27.

7. J. Fischer, Ein generisches Objektmodell zur Modellierung und Simulation operativer Entscheidungen in Produktionssystemen (Shaker Verlag, Aachen, 2004).

8. U. Jonsson, Ein integriertes Objektmodell zur durchlaufplanorientierten Simulation von Produktionssystemen (Shaker Verlag, Aachen, 2000).

9. G. Zülch, J. Fischer, and U. Jonsson, An integrated object model for activity network based simulation, in: WSC'00 Proceedings of the 2000 Winter Simulation Conference, Volume 1, edited by J. A. Joines, R. R. Barton, K. Kang and P. A. Fishwick (2000), pp. 371-380.

10. G. Zülch and P. Stock, Self-organizing manufacturing control based on the ant colony approach, in: Modeling and Implementing the Integrated Enterprise - Proceedings of the International Conference on Advances in Production Management Systems, edited by the IFIP WG 5.7 (CD-ROM, 2005).

11. A. Hax and G. Bitran, Hierarchical planning systems - a production application, in: Disaggregation: Problems in Manufacturing and Service Organizations, edited by L. P. Ritzman et al. (Martinus Nijhoff Publishing, Boston et al., 1979), pp. 63-93.

12. G. Zülch, Modelling and simulation of human decision-making in manufacturing system, in: Proceedings of the 2006 Winter Simulations Conference, edited by L. F. Perrone et al. (The Institute of Electrical and Electronics Engineers et al., Piscataway, NJ, 2006), pp. 947-953.

13. A. Klinger, Referenzmodelle für die Abbildung von Personalsteuerung in der Simulation (Society for Computer Simulation International, San Diego et al., 1999).

14. G. Reinhart and W. E. Lulay, Koordination dezentraler Produktionsstrukturen durch begleitende Simulation, Zeitschrift für wirtschaftlichen Fabrikbetrieb 93(1-2), 35-38 (1998).

15. J. Krüger, Entscheidungstheorie-basierte Simulation der Handlungsorganisation im Fertigungsbereich (Shaker Verlag, Aachen, 1999).

16. G. Zülch, T. Gamber and P. Stock, Analyse von Entscheidungssystemen im Fertigungsbereich mittels Simulation, in: Simulation und Visualisierung 2007, edited by T. Schulze, B. Preim and H. Schumann (SCS Publishing House, Erlangen, 2007), pp. 97-109.

17. G. Zülch and J. Fischer, Increasing the Flexibility of Working Times and Personnel Control in an Industrial Repair Work System (May 30, 2007); http://www.simserv.com/white_papers.php. 